\title{
DESENVOLVIMENTO DE YACON EM FUNÇ̃̃O DO NÍVEL DE SOMBREAMENTO EM SISTEMA DE PRODUÇÃO AGROECOLÓGICA
}

\author{
Ariany das Graças Teixeira ${ }^{1}$ \\ Tiago Pacheco ${ }^{2}$ \\ Magno do Carmo Parajára ${ }^{3}$ \\ Diego Mathias Natal da Silva ${ }^{4}$ \\ Fabio Luiz de Oliveira ${ }^{5}$
}

\begin{abstract}
Resumo: A yacon originária dos andes quando cultivada fora do seu habitat natural possui boa adaptabilidade ás adversidades climáticas e à diferentes altitudes. Entretanto, regiões com temperaturas altas, e maior intensidade luminosa, poderá acarretar limitações ao desenvolvimento das plantas. Dessa forma, objetivou-se avaliar os efeitos do sombreamento artificial sob desenvolvimento da yacon, no sul do estado do Espírito Santo. O experimento foi realizado na área experimental do IFES em Rive, localizada no município de Alegre, ES. O delineamento experimental adotado foi o inteiramente casualizado (DIC), sendo quatro tratamentos, seis épocas de coletas e cinco repetições, em esquema de parcelas subdivididas no tempo. Sendo o tratamento representado pelos três níveis de sombreamento (30, 50 e 70\%) e a pleno sol. Foram avaliados: altura de plantas, número de folhas e massa seca de rizóforos e raízes de reserva. 0 cultivo de yacon sob $30 \%$ de restrição de luz proporciona maior altura e maior acúmulo de massa seca de raízes de reserva.
\end{abstract}

Palavras-chave: Smallanthus sonchifolius; Radiação solar; Crescimento.

\footnotetext{
1 Doutoranda em produção vegetal/Universidade Federal do Espirito Santo, Brasil. E-mail: arianyteixeira@yahoo.com.br.

${ }^{2}$ Graduando em Agronomia/Universidade Federal do Espirito Santo, Brasil. E-mail: tiagopm931@hotmail.com. ${ }^{3}$ Graduando em Agronomia/Universidade Federal do Espirito Santo, Brasil. E-mail: magnocp1@hotmail.com.

4 Doutor em Produção vegetal/Universidade Federal do Espirito Santo, Brasil. E-mail: diegoufvjm@yahoo.com.br.

5 Professor/pesquisador/Universidade Federal do Espirito Santo, Brasil. E-mail: fabio.oliveira.2@ufes.br.
} 